\section{AL-FARABI \\ http://dergipark.gov.tr/farabi

Arrival Date: 00.00.0000

Published Date:

00.00 .0000
Volume

(5)

Issue (3)

Year (September 2020)

\title{
Temel Bilgisayar Eğitimi Alanında Uzaktan Eğitimde Kullanılan Sınav Türleriyle Cinsiyetler Arasındaki İlişkilerin İncelenmesi
}

Investigation of Correlations Among Exam Types Used in Distance Education on

\author{
Basic Computer Education Issue Regarding Genders
}

\section{Mehmet Fikret GELIBOLU ${ }^{1}$, Tolga GÜYER ${ }^{2}$}

\section{ÖZET}

Temel bilgisayar eğitimi alanında uzaktan eğitimde kullanılan çeşitli ölçme araçlarının başarıyı yordamada önemli bireysel farklardan olan cinsiyetler arasında nasıl bir benzerlik gösterdiğinin araştırıldığı bu çalışmada 4 ayrı tür sınav ve yıl sonu başarı puanı olmak üzere toplam 5 puan türü üzerinden ilişkilere bakılmıştır. Araştırmada kullanılan sınavlar bilgisayarlı uyarlanabilir sınav, bilgisayarlı uygulama sınavı, çoktan seçmeli test ve klasik tür sınavdan oluşmaktadır. Araştırmada uzaktan eğitimde kullanımı geniş kitlelerde verimli olmayan proje ödevleri ile portfolyo değerlendirme gibi yöntemler kapsam dışında tutulmuştur. Araştırma Gazi Üniversitesi İktisadi ve İdari Bilimler Fakültesinde 77 kadın 81 erkek toplamda 158 öğrenci üzerinde yürütülmüştür. Cinsiyet gruplarının ayrı ayrı her ölçüm puanı için ilişki matrisi hesaplanmıştır. Araştırma sonucunda elde edilen bulgulara göre bilgisayarlı uyarlanabilir sınavlar (Computer Adaptive Tests) ve çoktan seçmeli testlerin temel bilgisayar eğitimi alanında uzaktan eğitimde kullanılabilecek hem kadın hem de erkeklere hitap eden en verimli ve uygun ölçme araçları olduğu söylenebilir.

Anahtar Kelimeler: temel bilgisayar eğitimi, uzaktan eğitimde ölçme, cinsiyetlere göre ölçme ilişkileri

\begin{abstract}
In this study various measurement tools on basic computer education issue used in distance education are investigated for displaying how correlative results between genders, which are important individual differences, on predicting achievement from obtained 5 measurement points consists of 4 types of exams and semester passing grade points as an external validity criterion. Exam types used in research are computer adaptive test, practical exam, multiple-choice test and classical paper and pen type computerized test. In the research, project works and portfolio evaluation like methods which used in distance education are excluded because of their inadequacy on practical application on wider people. Research is held on 77 female 81 male total 158 students from Gazi University Faculty of Economics and Administrative Sciences. Correlation matrix for both gender types on every measurement points are calculated. Regarding the findings in the research it could be said that computer adaptive tests and multiple-choice tests are the most effective and appropriate measurement tools for both gender types in distance education on basic computer education issue.
\end{abstract}

Keywords: basic computer education, measurement in distance education, measurement correlations regarding genders

\section{GİRIŞ}

Temel bilgisayar kullanma becerisi günümüzde yaşamın her alanında bir gereklilik olarak karşımıza çıkmaktadır. Hem günlük hem de iş yaşamımızın vazgeçilmez bir parçası haline gelen bilgisayar kullanımının önemi gün geçtikçe artmakta, bilgisayarı verimli kullanmak, günlük yaşamımızda bize sağladığı kolaylıklardan yararlanmak karşılaşabileceğimiz çeşitli sorunları çözebilmek için temel bilgisayar eğitimine sahip olmak gerekmektedir. Ulusal düzeydeki istatistik verileri, ülke çoğunluğunun henüz yeterli düzeyde bilgisayar okur-yazarı olmadığını göstermektedir (Bozer, 2019;

\footnotetext{
${ }^{1}$ Dr. Öğr. Üyesi, Hatay Mustafa Kemal Üniversitesi Eğitim Fakültesi, fikretgelibolu @ hotmail.com, ORCID: 0000-0002-3780-3005

${ }^{2}$ Prof. Dr. Gazi Üniversitesi Gazi Eğitim Fakültesi, guyer@ gazi.edu.tr, ORCID NO: 0000-0001-9175-5043
} 
Çelik vd, 2008). Türkiye'de eğitime erişim ve nitelik açısından önemli eşitsizlikler bulunmaktadır (Kıbrıslığlu Uysal ve Gelbal, 2018). Bu eşitsizlikleri ortadan kaldırmak, eğitim gereksinimini ve nitelik artışını karşılamak için internet ve uzaktan eğitim önemli bir potansiyele sahiptir (Pandey ve Indrakanti, 2018). Dünyada internete dayalı uzaktan eğitimin en yaygın kullanıldığı alanlar arasında bilgisayar ve iletişim teknolojileri, işletme, mühendislik ve fen bilimleri yer almaktadır (Göktaş ve Kayri, 2005). Uzaktan eğitimin en önemli kısımlarından birisi de hiç kuşkusuz değerlendirme basamağıdır. Normal eğitimde olduğu gibi uzaktan eğitimde de düzey tespit, atama/yerleştirme ya da öz değerlendirme gibi pek çok amaç için ölçmeye gereksinim duyulmaktadır. Uzaktan öğretimde uygulamalı sınavlar, çoktan seçmeli sınavlar, uyarlanabilir sınavlar, proje ödevleri, portfolyo değerlendirme gibi ölçme araçları kullanılmaktadır. Uzaktan eğitimin kullanım nedenlerinden birisi geniş kitlelere ulaşmak olduğu için bu ölçme araçlarının bazıları çoğu zaman tercih edilmemektedir (İşman, 2011;Kaya, 2002). Örnek olarak kalabalık gruplarda gelişim dosyalarının planlanması, sürecin izlenmesi ve dosyaların oluşturulması, öğretmenin öğrencilere kılavuzluk etmesi zorlaşacağından kullanılmasının verimli olmayacağı dolayısıyla tercih edilmemesi gerektiği vurgulanmaktadır (Atılgan, Kan ve Doğan, 2007).

Bilgisayarlı uyarlanabilir sınavlar (computer adaptive tests) bireyin verdiği yanıtlara göre ortaya çıkan yani doğru yanıt vermişse güçlük düzeyi daha yüksek bir soru, eğer yanlış yanıt vermişse güçlük düzeyi daha düşük bir soruyla karşılaşarak tam olarak hangi bilgi/beceri düzeyinde olduğunu saptamaya çalışan bireye özelleşmiş sınavlardır. Sınav madde havuzundaki tüm soruların sorulması, belirli bir standart hata değerinin altına düşülmesi, madde bilgisi değerinin belirli bir değerin altına düşmesi ya da sabit bir soru sayısına ulaşılması gibi bir kararlılık ölçütüne ya da bir olasılık değerine varılıncaya kadar devam etmekte ardından o konu hakkında sınav sonlandırılmaktadır (Green, 2000; MartinveLazendic, 2018; Thissen ve Mislevy, 2000; Thompson, 2017).

Günümüzde eğitim alanında yapılan pek çok çalışma eğitimde bireysel farklılıkların dikkate alınmasının eğitimde niteliğin artmasındaki gerekliliğini göstermektedir (Ilgaz, 2018). Eğitimde bireysel farklar: cinsiyet, yaş, ilgi, yetenek, kişilik yapıları, önbilgi düzeyi, öğrenme stilleri, öğrenme hızı, fiziksel ve duygusal durumlar, ihtiyaçlar, denetim odağı, engel durumları, grup uyumu, inançlar gibi sayısı giderek artan çeşitlilikte karşımıza çıkmaktadır (Demir, 2019; Topkaya ve Çelik, 2009). Bireysel farkların içinde en önemlilerinden birisi hiç kuşkusuz cinsiyet etmenidir. Cinsiyet hem beyin gelişimi ve fizyolojisini ilgilendiren ve dolayısıyla bireyin düşünme ve öğrenme biçiminde farklar yaratan bir kavram olmakla birlikte hem de sosyolojik ve kültürel roller açısından da bireyler arasında farkl11ıklara neden olmaktadır (Brueggeman, Thomas, Koomar, Hoskinsve Michaelson, 2020; Chen, Yang ve Hsiao, 2016; Nollenberger, Rodríguez-Planas ve Sevilla, 2016). Bundan dolayı eğitimin öğretim aşamasında olduğu gibi değerlendirme aşamasında kullanılan yöntemlerde de en büyük bireysel farklılıklardan olan cinsiyetin dikkate alınması önemlidir.

$\mathrm{Bu}$ çalışmada temel bilgisayar öğretiminde aynı örneklem ve konu aralığında bilgisayarlı uyarlanabilir sınav, bilgisayarlı uygulamalı sınav, klasik tür başarı sınavı, çoktan seçmeli sınav ve yıl sonu geçme puanlarıyla cinsiyetler arasındaki ilişki araştırılmıştır. Kullanılan dört ölçme aracının yanı sıra öğrencilerin bilgisayar dersi yıl sonu geçme notları da dış geçerlilik ölçütü olarak kullanılmıştır.

\section{YÖNTEM}

Araştırmanın bağımlı değişkenini başarı, bağımsız değişkenlerini kullanılacak (klasik tür sınavı, çoktan seçmeli sınav, uygulamalı sınav, bilgisayarlı uyarlanabilir sınav) ölçme yöntemleri oluşturmaktadır. Araştırmada cinsiyetlere göre ilişkinin araştırıldığı tek değişkenli faktöriyel desen kullanılmıştır. 


\section{Veri Toplama Araçları}

Araştırmada kullanılan bilgisayarlı uyarlanabilir sınavın soru havuzu 134 temel bilgisayar eğitimi sorusundan oluşmakta ve iki parametreli (güçlük ve ayırt edicilik değerlerine bağl1) lojistik modele göre kalibre edilmiştir. Madde seçim algoritmasında katılımcılar hakkında bir ön bilgiye gereksinim duyma gibi bir sınırlılığı olan Bayes yöntemi yerine en yüksek olabilirlik (maximum likelihood) yönteminin kullanılması tercih edilmiştir. Çoktan seçmeli test 30 maddeden oluşmakta ve 0,80 cronbach alpha güvenilirlik değerine sahiptir. Klasik sınavın ve uygulama sınavının geçerlilikleri alan uzmanlarının görüşleri alınarak ve pilot puanlama güvenilirliği yapılarak sağlanmıştır. Kullanılan tüm sınavlar aynı konu aralığına sahiptir ve bilgisayarlı uyarlanabilir sınavın yapısı gereği uygun olmamasından dolayı o hariç diğer bütün sınavlarda konu dağılımları ve buna göre puanlama ağırlığı denk tutulmuştur.

\section{Çalışma Grubu}

Veriler 2015 Mayıs ayında Gazi Üniversitesi İktisadi ve İdari Bilimler Fakültesinde temel bilgisayar dersi alan gönüllü öğrencilerden toplanmıştır. Diğer fakültelere göre kadın-erkek dağılımının ve sayısal-sözel ağırlığının dengeli bir fakülte olması, bilgisayar laboratuvarı olanakları ve öğrenci sayısının fazlalığı gibi etmenler örneklem seçiminde dikkate alınan başlıca nedenleri oluşturmaktır. Tüm sınav verilerinin elde edilemediği katılımcılar ayıklandığında kalan 77 kadın 81 erkek toplam 158 öğrenci üzerinde veriler analiz edilerek yorumlanmıştır.

\section{Verilerin Analizi}

Verilerin analizinde kullanılacak analiz yöntemini belirlemek için parametrik varsayımlar öncelikle sınanmıştır. Normal dağılımı test etmek için en güvenilir yöntemlerden olan Shapiro-Wilk testi kullanılmıştır. Normallik ve diğer parametrik test varsayımlarını sağlayan veriler Pearson korelasyonu, sağlamayan veriler Spearman korelasyon değerleri hesaplanarak incelenmiştir.

\section{BULGULAR}

Tablo 1:Kadın Katılımcıların Puanlarının Normal Dağılım Tablosu

\begin{tabular}{lccccc}
\hline Puanlar & $\begin{array}{c}\text { Yıl sonu } \\
\text { puanı }\end{array}$ & $\begin{array}{c}\text { Bilgisayarlı } \\
\text { uyarlanabilir } \\
\text { sınav }\end{array}$ & $\begin{array}{c}\text { Uygulama } \\
\text { sınavı }\end{array}$ & $\begin{array}{c}\text { Çoktan } \\
\text { seçmeli test }\end{array}$ & Klasik sınav \\
\hline $\mathbf{N}$ & 77 & 77 & 77 & 77 & 77 \\
$\mathbf{X}$ & 69,41 & $-1,49$ & 40,46 & 14,12 & 40,98 \\
SS & 9,02 & 1,08 & 9,03 & 6 & 17,83 \\
Shapiro-Wilk & 0,992 & 0,920 & 0,978 & 0,935 & 0,980 \\
$\mathbf{p}$ & $.927^{*}$ & .000 & $.212^{*}$ & .001 & $.250^{*}$ \\
\hline
\end{tabular}

$* p>.05$

Tablo 1'de kadınların verilerinin normallik testi sonuçlarında "klasik sınav", "uygulama sınavı" ve "yıl sonu" puanları normal dağılım gösterdiği diğer verilerin çarpık dağılım gösterdiği görülmüştür. Buna göre "klasik sınav", "uygulama sınavı" ve "yıl sonu" puanlarının birbirleri arasındaki korelasyon işlemlerinde parametrik Pearson korelasyonu tercih edilmiş diğer korelasyon katsayılarının hesaplanmasında parametrik olmayan Spearman korelasyon değerleri kullanılmıştır. 
Tablo 2:Erkek Katılımcıların Puanlarının Normal Dağılım Tablosu

\begin{tabular}{lccccc}
\hline Puanlar & $\begin{array}{c}\text { Yıl sonu } \\
\text { puanı }\end{array}$ & $\begin{array}{c}\text { Uyarlanabilir } \\
\text { sınav }\end{array}$ & $\begin{array}{c}\text { Uygulama } \\
\text { sınavı }\end{array}$ & $\begin{array}{c}\text { Çoktan } \\
\text { seçmeli test }\end{array}$ & Klasik sınav \\
\hline $\mathbf{N}$ & 81 & 81 & 81 & 81 & 81 \\
$\mathbf{X}$ & 76,06 & 0,47 & 42,54 & 19 & 47,75 \\
SS & 10,53 & 2,04 & 11,96 & 4,88 & 13,11 \\
Shapiro-Wilk & 0,963 & 0,978 & 0,902 & 0,957 & 0,966 \\
$\mathbf{p}$ & .020 & $.184^{*}$ & .000 & .008 & .031 \\
\hline
\end{tabular}

$* p>.05$

Tablo 2'de verilerin korelasyon sınaması öncesinde yapılan Shapiro-Wilk normallik testi sonuçlarına göre erkeklerde yalnızca "uyarlanabilir sınav" puanlarının normal dağıldığı diğer verilerin çarpık bir dağılım gösterdiği görülmüştür. Bundan dolayı parametrik olmayan Spearman korelasyonu kullanılmıştır.

Tablo 3: Cinsiyetlere Göre Sınav Puanları Korelasyon Dağılımları

\begin{tabular}{|c|c|c|c|c|c|}
\hline $\begin{array}{l}\text { Korelasyonlar } \\
\mathbf{N}_{E}=\mathbf{8 1}, \mathbf{N}_{\mathrm{K}}=\mathbf{7 7}\end{array}$ & $\begin{array}{c}\text { Yil sonu } \\
\text { puanı }\end{array}$ & $\begin{array}{c}\text { Uyarlanabilir } \\
\text { sinav }\end{array}$ & $\begin{array}{c}\text { Uygulama } \\
\text { sinavı }\end{array}$ & $\begin{array}{c}\text { Çoktan seçmeli } \\
\text { test }\end{array}$ & $\begin{array}{c}\text { Klasik } \\
\text { Sinav }\end{array}$ \\
\hline Yıl sonu puanı (E) & 1 & 0,72 & 0,57 & 0,67 & 0,50 \\
\hline Yıl sonu puanı (K) & 1 & 0,46 & $0,01^{*}$ & 0,53 & $0,32 *$ \\
\hline $\begin{array}{c}\text { Uyarlanabilir sinav } \\
\text { (E) }\end{array}$ & 0,72 & 1 & 0,59 & 0,77 & 0,54 \\
\hline $\begin{array}{c}\text { Uyarlanabilir sınav } \\
\text { (K) }\end{array}$ & 0,46 & 1 & 0,14 & 0,52 & 0,45 \\
\hline Uygulama sınavı (E) & 0,57 & 0,59 & 1 & 0,51 & 0,39 \\
\hline Uygulama sınavı (K) & $0,01 *$ & 0,14 & 1 & 0,23 & $0,25 *$ \\
\hline $\begin{array}{l}\text { Çoktan seçmeli test } \\
\text { (E) }\end{array}$ & 0,67 & 0,77 & 0,51 & 1 & 0,62 \\
\hline $\begin{array}{c}\text { Çoktan seçmeli test } \\
\text { (K) }\end{array}$ & 0,53 & 0,52 & 0,23 & 1 & 0,63 \\
\hline Klasik sınav (E) & 0,50 & 0,54 & 0,39 & 0,62 & 1 \\
\hline Klasik sınav (K) & $0,32 *$ & 0,45 & $0,25 *$ & 0,63 & 1 \\
\hline
\end{tabular}

*Pearson parametrik korelasyon değerleri

Tablo 3 incelendiğinde yıl sonu ders geçme puanları ile çevrim içi uyarlanabilir test puanları erkeklerde yüksek korelasyon $(r=0,72 ; p<.01)$ gösterirken, kadınlarda orta düzey korelasyon $(r=0,46$; $p<.01)$ göstermektedir. Yıl sonu ders geçme puanlarıyla uygulama sınavi ilişkisine bakıldığında erkeklerde orta düzey $(r=0,57 ; p<.01)$, kadınlarda $(r=0,01 ; p>.05)$ ise anlamlı bir korelasyon elde edilememiştir. Yıl sonu ders geçme puanlarıyla çoktan seçmeli test puanları incelendiğinde erkeklerde yükseğe yakın orta düzey korelasyon $(r=0,67 ; p<.01)$, kadınlarda orta düzey korelasyon $(r=0,53 ; p<.01)$ görülmektedir. Y1l sonu ders geçme puanlarıyla klasik sınav puanları incelendiğinde erkeklerde orta düzey $(r=0,50 ; p<.01)$, kadınlarda düşüğe yakın orta düzey korelasyon $(r=0,32$; $p<.01)$ gözlenmektedir.

$\mathrm{Bu}$ verilere göre araştırmada kullanılan dış geçerlilik ölçütü olan yıl sonu ders geçme puanlarına en benzer ölçümü yapan sınav türünün erkeklerde çevrim içi uyarlanabilir sınav olduğu gözlenirken kadınlarda çoktan seçmeli testlerin az bir farkla da olsa çevrim içi uyarlanabilir sınavlardan daha benzer sonuç verdiğini ortaya koymaktadır. Uygulama sınavı değerlerine bakıldığında yıl sonu ders geçme puanları erkeklerde orta düzey korelasyon gösterirken kadınlarda anlamlı ilişki elde edilememiştir. 
Çevrim içi uyarlanabilir sınavlarla diğer sınav türlerinin cinsiyetlere göre korelasyonları incelendiğinde; erkeklerde uygulama sinavlarıyla orta düzey korelasyon $(r=0,59 ; p<.01)$ gözlemlenirken kadınlarda anlamlı bir korelasyon $(r=0,14 ; p>.05)$ değerine ulaşılamamıştır. Çevrim içi uyarlanabilir sınav puanları, çoktan seçmeli sınav puanlarıyla erkeklerde yüksek korelasyon $(r=0,77 ; p<.01)$ gösterirken, kadınlarda orta düzey korelasyon $(r=0,52 ; p<.01)$ göstermektedir. Çevrim içi uyarlanabilir sınavlar, klasik sınavlarla erkeklerde $(r=0,54 ; p<.01)$ ve kadınlarda $(r=0,45$; $p<.01$ ) orta düzeyde korelasyon göstermektedir.

$\mathrm{Bu}$ verilere göre uyarlanabilir sınavlara en benzer ölçümlerin hem erkekler hem de kadınlarda çoktan seçmeli test sınavlarından elde edildiği gözlenmektedir. Ancak uyarlanabilir sınavların erkeklerde uygulama sınavları yerine kullanılabilirliğinden söz edilebilse de kadınlarda anlamlı bir ilişki değerine ulaşılamamıştır.

Uygulama sınavların cinsiyetlere göre diğer sınav türleriyle olan ilişkisine bakıldığında; erkeklerde uyarlanabilir sinavlar $(r=0,59 ; p<.01)$, çoktan seçmeli testler $(r=0,51 ; p<.01)$ ve klasik sinavlarla $(r=0,39 ; p<.01)$ orta düzey korelasyon gösterirken kadınlarda uyarlanabilir sınavlarla $(r=0,14 ; p>.05)$ anlamsız, çoktan seçmeli testler $(r=0,23 ; p<.05)$ ve klasik sınavlarla $(r=0,25 ; p<.05)$ düşük düzey korelasyon gösterdiği gözlenmektedir.

Buna göre erkeklerde uygulama sınavları yerine kullanılabilecek alternatif sınav türleri çevrim içi uyarlanabilir sınavlar $>$ çoktan seçmeli testler $>$ klasik sınavlar şeklinde bir sıra izlemekteyken kadınlarda tam tersi klasik sınavlar $>$ çoktan seçmeli testler $>$ çevrim içi uyarlanabilir sınavlar şeklinde bir sira izlemektedir.

Çoktan seçmeli testlerin diğer sınav türleriyle cinsiyetlere göre ilişkisine bakıldı̆̆ında; erkeklerde çevrim içi uyarlanabilir sınav puanları arasında yüksek korelasyon $(r=0,77 ; p<.01)$ varken kadınlarda orta düzey korelasyon $(r=0,52 ; p<.01)$ bulunmaktadır. Çoktan seçmeli testler erkeklerde uygulama sinavlarıyla orta düzey bir korelasyon $(r=0,51 ; p<.01)$ gösterirken, kadınlarda düşük korelasyon $(r=0,23 ; p<.05)$ göstermektedir. Çoktan seçmeli sınavlar ve klasik sınav puanları hem erkeklerde $(r=0,62 ; p<.01)$ hem de kadınlarda $(r=0,63 ; p<.01)$ çok benzer orta düzey korelasyon göstermektedir.

Buna göre erkeklerde özellikle uzaktan eğitimde yaygın kullanılan çoktan seçmeli testlerin yerine ölçüm benzerliği açısından çevrim içi uyarlanabilir testler iyi bir alternatif oluştururken kadınlarda klasik sinavlar da tercih edilebilir.

Klasik sınavların diğger sınav türleriyle cinsiyetlere göre ilişkileri incelendiğinde; erkeklerde ( $r=0,54$; $p<.01)$ ve kadınlarda $(r=0,45 ; p<.01)$ orta düzey korelasyon göstermektedir. Klasik sınav puanları uygulama sınavı puanlarıyla erkeklerde orta düzey $(r=0,39 ; p<.01)$ korelasyon gösterirken kadınlarda $(r=0,25 ; p<.05)$ düşük düzey korelasyon göstermektedir. Klasik sinavlar çoktan seçmeli testlerle erkeklerde $(r=0,62 ; p<.01)$ ve kadınlarda orta düzey $(r=0,63 ; p<.01)$ korelasyon göstermektedir.

\section{SONUÇ VE YORUMLAR}

Çalışma birden fazla ölçümü temel aldığı için katılımcıların yıl sonu puanları, başarıyı yordamada en geçerli kaynaklardan biri olacağı varsayımıyla dış geçerlilik ölçütü olarak kullanılmıştır. Buna göre kadınlarda yıl sonu puanlarıyla en yüksek ilişkiyi gösteren çoktan seçmeli sınav ve uyarlanabilir sınav az bir farkla en yüksek yordayıcılığa sahipken erkeklerde az bir farkla uyarlanabilir sınav, çoktan seçmeli sınav sırasıyla en yüksek yordayıcılığa sahip olduğu bulunmuştur. Yani hem erkeklerde hem de kadınlarda temel bilgisayar eğitiminde uzaktan eğitimde kullanılabilecek en uygun ölçme araçlarının uyarlanabilir sınav ve çoktan seçmeli sınav olduğu ve aralarında cinsiyete yönelik önemli bir fark bulunmadı ̆̆ı söylenebilir.

Temel bilgisayar eğitiminde yıl sonu puanı haricinde uygulama sınavı da pek çok kazanımın dolaylı değil de doğrudan ölçülebilmesine olanak sağladığı için dikkate alınması gereken bir diğer sınav türüdür. Uygulama sınavıyla en benzer yordayıcılığa sahip sınav türünün erkeklerde uyarlanabilir sınav, kadınlarda ise klasik tür sınav olduğu görülmektedir. Ancak kadınların bütün sınav puanlarının 
uygulama sınavıyla düşük ilişkiye sahip olması yine de uygulama sınavı yerine kullanılabilecek en uygun aracın yordayıcılığı hakkında cinsiyete yönelik fark bulunduğu yorumunu yapmanın uygun olmayabileceğini göstermektedir.

Araştırma bulguları 1şığında uyarlanabilir sınavların hem ölçüm geçerliliği hem de her iki cinsiyete de hitap etme konusunda temel bilgisayar eğitiminde uzaktan eğitimde yaygın kullanılan çoktan seçmeli sınavlar yerine kullanılabilecek en uygun ölçme aracı olduğu söylenebilir.

\section{KAYNAKÇA}

Atılgan, H. (Ed.)., Kan, A., Doğan, N. (2007). Eğitimde ölçme ve değerlendirme. Anı Yayıncılık, Ankara

Bozer, R. (2019). Teknoloji Okuryazarlığı ve Türkiye İstatistik Kurumu ile Yetişkin Yeterliliklerinin Uluslararası Değerlendirilmesi Programı Verileri Kapsamında Ülkemizde Teknoloji Kullanım Durumu. Yetişkin Ĕ̈itimi Dergisi, 2(2-3).

Brueggeman, L., Thomas, T. R., Koomar, T., Hoskins, B., Michaelson, J. J. (2020). Sex Differences in the Brain: Divergent Results from Traditional Machine Learning and Convolutional Networks. In 2020 IEEE 17th International Symposium on Biomedical Imaging (ISBI) (pp. 1-4). IEEE.

Chen, S. C., Yang, S. J., Hsiao, C. C. (2016). Exploring student perceptions, learning outcome and gender differences in a flipped mathematics course. British Journal of Educational Technology, 47(6), 1096-1112.

Çelik, F., Kocaman, F., Önal, A.S. (2008). Burdur ili merkez ilçe ilköğretim öğretmenlerinin bilgisayar okur-yazarlık seviyeleri. Mehmet Akif Üniversitesi Ĕgitim Fakültesi Dergisi, 15, 1-13.

Demir, Ö. (2019). Eşli Programlamada Çeşitli Bireysel Farklılıkların Grup Uyumu, Akış ve Kodlama Performansına Etkisi.(Doktora Tezi). Hacettepe Üniversitesi Eğitim Bilimleri Enstitüsü, Ankara

Gökdaş, İ., Kayri, M. (2005). E-öğrenme ve Türkiye açısından sorunlar, çözüm önerileri. Yüzüncü Yıl Üniversitesi Ĕ̆itim Fakültesi Dergisi, 2(2)

Green, B.F. (2000). "System design and operation.”,Computerized Adaptive Testing: A Primer. (Ed. H. Wainer), Mahwah, NJ: Lawrence Erlbaum Associates

Ilgaz, H. (2018). Bireysel Farklılıklar Kapsamında Çevrimiçi Öğrenme Araştırmalarına İlişkin Sistematik Bir Derleme. Journal of TheoreticalEducationalScience/Kuramsal Eğitimbilim Dergisi, 11(4).

İşman, A. (2011). Uzaktan eğitim4. Baskı. Pegem Yayınları, Ankara

Kaya, Z. (2002). Uzaktan eğitim.Pegem Yayınları, Ankara

Kıbrıslıoğlu Uysal, N., Gelbal, S. (2018). Pisa ve Tüik Verileri Çerçevesinde Türkiye'de Eğitimde Eşitsizlik. Kastamonu Eğitim Dergisi, 26(4), 1195-1206.

Martin, A. J., Lazendic, G. (2018). Computer-adaptive testing: Implications for students' achievement, motivation, engagement, and subjective test experience. Journal of educational psychology, 110(1), 27.

Nollenberger, N., Rodríguez-Planas, N., Sevilla, A. (2016). Themathgendergap: The role of culture. AmericanEconomicReview, 106(5), 257-61.

Pandey, U. C., Indrakanti, V. (Eds.). (2018). Open andDistance Learning InitiativesforSustainable Development. IGI Global.

Thissen, D., Mislevy, R.J. (2000). “Testing algorithms.”,Computerized adaptive testing: a primer. (Ed. H. Wainer), Mahwah, NJ: Lawrence Erlbaum Associates. 
Thompson, G. (2017). Computer adaptive testing, big data and algorithmic approaches to education. British journal of sociology of education, 38(6), 827-840.

Topkaya, E. Z., Çelik, H. (2009). Eğitimde Bireysel Farklılıklar. Eğitimde Kuram ve Uygulama, 5(2), 316-321. 